\title{
Citric Acid Administration Protects Against Insulin-Induced Hypoglycemic Brain and Liver Injury
}

\author{
*OMAR M.E. ABDEL-SALAM ${ }^{1}$, EMAN R. YOUNESS ${ }^{2}$, AMANY AMEEN SLEEM $^{3}$, \\ FATMA A. MORSY ${ }^{4}$ \\ Department of Toxicology and Narcotics ${ }^{1}$, Medical Biochemistry ${ }^{2}$, Pharmacology $^{3}$, Pathology ${ }^{4}$, \\ Medical Research and Clinical Studies Institute, National Research Centre, Tahrir Street, Cairo, \\ EGYPT
}

\begin{abstract}
We aimed to investigate the effect of treatment with citric acid on oxidative stress and tissue injury in brain and liver of rats subjected to hypoglycaemia. Rats received intraperitoneal injections of insulin (5 IU $/ \mathrm{kg}$ ) followed $30 \mathrm{~min}$ later by oral administration of saline or citric acid at doses of $0.2,0.4 \mathrm{or} 1 \mathrm{~g} / \mathrm{kg}$. Rats were euthanized $1 \mathrm{~h}$ after insulin injection and their brains and livers were dissected out for biochemical studies including determination of malondialdehyde (MDA), reduced glutathione (GSH), nitric oxide (NO), paraoxonase-1 (PON-1), 5-lipoxygenase, and cholinesterase. Serum alanine aminotransferase and aspartate aminotransferase were determined and histological investigations for the liver were carried out. Results indicated that in insulin only treated rats, MDA and NO levels were significantly increased whereas GSH content and PON-1 activity significantly decreased in brain and liver tissue. In addition, cholinesterase activity significantly decreased while 5-lipoxygenase increased in brain with respect to the saline control group after insulin injection. Serum aminotransferases showed significant elevation in insulin-treated rats together with distorted hepatic architecture, hydropic degeneration, and extensive cytoplasmic vacuolation of hepatocytes. The biochemical alterations in the brain and liver of hypoglycaemic rats were markedly alleviated in a dosedependant manner by the administration of citric acid which also markedly reduced the histological liver injury with the group treated with insulin and citric acid at $1 \mathrm{~g} / \mathrm{kg}$ exhibiting more or less preserved hepatic architecture. These results indicate that citric acid was effective in alleviating the biochemical alterations in brain and liver and protecting against liver injury during hypoglycaemia. It could thus prove of benefit in patients on insulin therapy with accidental hypoglycaemia from over dosing.
\end{abstract}

Key-Words: - insulin; hypoglycaemia; liver injury; oxidative stress

Received: April 2, 2021. Revised: November 22, 2021. Accepted: December 19, 2021. Published: February 1, 2022.

\section{Introduction}

Insulin-induced hypoglycaemia is a well-known complication of insulin therapy, often due to an over dosage. It usually occurs in diabetic patients attempting to achieve tight control of their blood glucose level. Hypoglycaemia if severe can result in serious brain injury [1]. Animal studies have shown that severe hypoglycemia induces neuronal death in brain vulnerable regions and impairs cognitive functions eg., spatial learning and memory [2-5]. Since the brain iss unable to synthesize glucose or keep substantial amounts as glycogen in astrocytes, the depends on continuous supply of glucose from the blood circulation. The decline in blood glucose level and consequently the delivery of glucose into the brain deprives neurons from their main fuel, resulting in depletion of energy substrates, energy failure, and ultimately neuronal death [6].The latter is largely attributable to several pathogenetic mechanisms that include oxidative stress, release of glutamate, release of the excitatory amino acid aspartate and excitotoxic injury, release of zinc, induction of the mitochondrial permeability transition and activation of poly (ADP-ribose) polymerase $[1,6]$.

Oxidative stress is considered an important contributor to neuronal cell death during severe hypoglycaemia [5,7]. An increase in lipid peroxidation and nitric oxide has been demonstrated in the brain of hypoglycaemic mice and rats [9-10]. The main source of reactive oxygen species (ROS) in the cell is the mitochondria where leakage of electrons from the mitochondrial respiratory chain onto $\mathrm{O}_{2}$ results in the formation of superoxide $\left(\mathrm{O}_{2}{ }^{-}\right)$ which can be converted to hydrogen peroxide by superoxide dismutase. The reaction of $\mathrm{H}_{2} \mathrm{O}_{2}$ with the reduced forms of the transition metal ions (e.g., 
$\left.\mathrm{Fe}^{2+}, \mathrm{Cu}^{+}\right)$results in the strong oxidant hydroxyl radical $(\mathrm{HO} \bullet)$ [11]. In addition, the reaction of $\mathrm{O}_{2}$ with NO generates peroxynitrite $\left(\mathrm{ONOO}^{-}\right)$. ROS can also be produced by NADPH-dependent oxidase of activated phagocytes, lipoxygenase and cyclooxygenase, xanthine oxidase, myeloperoxidase. The increase in ROS can target mitochondrial structures causing oxidative damage and mitochondrial dysfunction that in turn causes an increased generation of free radicals $[11,12]$. Since the mitochondria are the source of energy supply to cells through oxidative phosphorylation, their dysfunction will result in impairment of essential cellular processes [13].

Citric acid is an important intermediate in the metabolism of mammalian cells. It is synthesized in the mitochondria from acetyl-CoA and oxaloacetate by citrate synthase, and enters the tricarboxylic acid (TCA), Krebs or citric acid cycle, whose main function is the provision of reducing equivalents for the mitochondrial respiratory chain, which in turn produces most of the energy used by the cell in the form of adenosine 5'-triphosphate (ATP) [14]. Citric acid is a dietary component being present in large amounts in citrus fruits such as lemon, orange, and gape fruit [15]. It is also used as a food preservative because of its antioxidant properties and in soft drinks to give sour taste [16]. Studies showed that citric acid decreases lipid peroxidation and downregulates inflammation by reducing polymorphonuclear cell degranulation, attenuating the release of myeloperoxidase, elastase, interleukin (IL)-1 $\beta$, platelet factor 4 [17-19], tumour necrosis factor- $\alpha$ (TNF- $\alpha)[20]$, and nuclear factor-kappa B (NF-kB) [21]. Citric acid demonstrated protective effect against brain and liver injury caused by lipopolysaccharide (LPS) endotoxin [20], malathion [22], rotenone [21], toluene [23] or carbon tetrachloride $[24,25]$.

Therefore, the present study was designed to investigate whether the administration of citric acid would be able to protect against oxidative stress in the brain and liver of rats subjected to insulininduced hypoglycaemia. The liver is also susceptible to severe hypoglycaemia. The liver of mice subjected to insulin-induced hypoglycaemia showed necrosis and cytoplasmic vacuolation of hepatocytes [10]. Thus, the effect of citric acid on the liver histology in hypoglycaemic rats was also evaluated.

\section{Materials and Methods}

\subsection{Animals}

Sprague-Dawley rats of both sexes, weighing 130 $140 \mathrm{~g}$, from the animal house colony of the National Research Centre (NRC) were used in the study and fed with standard laboratory chow and water $a d$ libitum.

\subsection{Drugs and Chemicals}

Mixtard ${ }^{\circledR} 30$ insulin (Novo Nordisk, France), consisting of human insulin soluble and human isophane insulin (70/30) and citric acid (Sigma, USA) were used and diluted in $0.9 \%$ saline to obtain the necessary dose). Citric acid (Sigma, USA) was used and dissolved in saline to obtain the necessary doses.

\subsection{Experimental Design}

Different groups of rats ( $n=6$ each) were used. Rats were randomly assigned to the following treatment groups:

Group 1 received saline and served as negative control.

Group 2 were treated with insulin at the dose of 5 IU/kg, intraperitoneally (i.p.).

Groups 3-5 were treated with insulin at the dose of 5 IU/kg, i.p., and followed $30 \mathrm{~min}$ later by administration of citric acid orally at doses of 0.2 , 0.4 or $1 \mathrm{~g} / \mathrm{kg}$.

Blood samples were obtained from the retro-orbital venous plexus under light ether anesthesia $3 \mathrm{~h}$ after insulin injection for the determination of alanine aminotransferase (ALT) and aspartate aminotransferase (AST) activities in serum. Rats were subsequently euthanized by decapitation $1 \mathrm{~h}$ after insulin injection and their brains and livers were rapidly removed out on an ice-cold plate, washed with ice-cold phosphate-buffered saline at $\mathrm{pH} 7.4$, and weighed. Tissue samples were stored at $-80{ }^{\circ} \mathrm{C}$ until further processing. Tissue homogenization was done with $0.1 \mathrm{M}$ phosphatebuffered saline ( $\mathrm{pH}$ 7.4) to give a final concentration of $10 \%$ weight/volume. The supernatant was stored at $-80{ }^{\circ} \mathrm{C}$ until further analysis. Biochemical markers of oxidative stress including MDA, GSH, nitric oxide, paraoxonase-1 in brain and liver, and 5lipoxygenase, and cholinesterase in brain were estimated at end of the treatment period. The histopathological study was carried out on separate groups of rats ( $\mathrm{n}=4$ per group). 


\subsection{Biochemical Assessments}

\subsubsection{Lipid Peroxidation}

Lipid peroxidation was measured by determination of malondialdehyde (MDA) in the brain homogenates [26]. Thiobarbituric acid reactive substances (TBAS) react with thiobarbituric acid forming TBA-MDA adduct and the absorbance is read at $532 \mathrm{~nm}$ using spectrophotometer.

\subsubsection{Nitric Oxide}

Nitric oxide, estimated as nitrate/nitrite was determined using the Griess reaction. In this assay nitrate is converted to nitrite via nitrate reductase. Griess reagent then acts to convert nitrite to a deep purple azo compound that can be determined using spectrophotometer at $540 \mathrm{~nm}$ [27].

\subsubsection{Reduced Glutathione}

Reduced glutathione (GSH) was determined in homogenates according to Ellman [28]. Briefly, DTNB (5,5'-dithiobis (2-nitrobenzoic acid) or Ellman's reagent is reduced by the free sulfhydryl group on GSH molecule to generate 5-thio-2nitrobenzoic acid which has yellow color and can be determined by reading absorbance at $412 \mathrm{~nm}$.

\subsubsection{Paraoxonase-1}

The arylesterase activity of PON-1 was determined by a colorimetric method using phenyl acetate as a substrate. In this assay, PON-1 catalyzes the cleavage of phenyl acetate resulting in phenol formation. The rate of formation of phenol was measured by monitoring the increase in absorbance at $270 \mathrm{~nm}$ at $25^{\circ} \mathrm{C}$. The working mix consisted of 20 mMTris/ $\mathrm{HCl}$ buffer, $\mathrm{pH} 8.0$, containing $1 \mathrm{mM}$ $\mathrm{CaCl}_{2}$ and $4 \mathrm{mM}$ phenyl acetate as the substrate. Samples diluted 1:3 in buffer were added to the above mix and the changes in absorbance were recorded following a $20 \mathrm{~s}$ lag time. One unit of arylesterase activity is equal to $1 \mu$ mole of phenol formed per min. The PON-1 activity is expressed in $\mathrm{kU} / \mathrm{l}$, based on the extinction coefficient of phenol of $1310 \mathrm{M}^{-1} \mathrm{~cm}^{-1}$. Blank samples containing water were used to correct for the spontaneous hydrolysis of phenyl acetate [29].

\subsubsection{Cholinesterase Activity}

Butyrylcholinesterase (BChE) activity was measured with a commercially available kit (Ben Biochemical Enterprise, Milan, Italy). BChE catalyzes the hydrolysis of butyrylthiocholine as a substrate into butyrate and thiocholine. The latter reacts with 5,5'-dithiobis (2-nitrobenzoic acid) (DTNB) to produce a yellow chromophore which then could be quantified using a spectrophotometer [30].

\subsubsection{5-lipoxygenase}

5-Lipoxygenase was determined using a doubleantibody sandwich enzyme-linked immunosorbent assay (ELISA) kit from Shanghai Sunred Biological Technology (Shanghai, China).

\subsubsection{Serum Liver Enzymes}

The activities of the liver enzymes alanine aminotransferase (ALT) and aspartate aminotransferase (AST) in serum were measured according to Reitman-Frankel colorimetric transaminase procedure using commercially available kits from BioMérieux, France [31].

\subsection{Histopathological Assessments}

The brain and liver from the control and treated groups were fixed with $10 \%$ formalin and embedded in paraffin wax and cut into longitudinal sections of $5 \mu \mathrm{m}$ thickness. The sections were stained with Hemotoxylin and Eosin (Hx\& E) dye for histopathological observations.

\subsection{Statistical Analysis}

All data were expressed as the mean \pm SEM. Data were analyzed by one-way analysis of variance (ANOVA) followed by followed by Tukey's multiple comparisons test. GraphPad Prism 6 for Windows (GraphPad Prism Software Inc., San Diego, CA, USA) was used. Statistical significance was considered at a probability value of less than 0.05 .

\section{Results}

\subsection{Brain Oxidative Stress}

\subsubsection{Lipid Peroxidation}

Compared with rats receiving saline, rats that received insulin alone showed significantly increased brain MDA by $39.1 \%(22.87 \pm 0.84$ vs $16.44 \pm 0.73 \mathrm{nmol} / \mathrm{g}$. tissue). In insulin/citric acid treated groups, the level of MDA significantly decreased by $14.4 \%, 24.7 \%$ and $27.4 \%$ (from 22.87 \pm 0.84 to $19.58 \pm 0.41,17.21 \pm 0.47$ and $16.60 \pm$ $0.76 \mathrm{nmol} / \mathrm{g}$. tissue) (Fig. 1).

\subsubsection{Nitric Oxide}

In rats treated with only insulin, the level of nitric oxide increased by $65.3 \%(33.0 \pm 1.0$ vs. $19.96 \pm$ 
$0.83 \mu \mathrm{mol} / \mathrm{g}$. tissue) compared with the saline group. Brain nitric oxide levels were significantly decreased by $18.7 \%, 35.9 \%$ and $40.7 \%$ (from $33.0 \pm$ 1.0 in the insulin only group to $26.83 \pm 1.2,21.16 \pm$ 0.81 and $19.57 \pm 0.47 \mu \mathrm{mol} / \mathrm{g}$. tissue in the insulin/citric acid treated groups) (Fig. 1).

\subsubsection{Reduced Glutathione}

Insulin-treated rats showed significant decrease in brain GSH content by $65.5 \%$ from $3.39 \pm 0.22$ $\mu \mathrm{mol} / \mathrm{g}$. tissue in the saline treatment group to 1.17 $\pm 0.08 \mu \mathrm{mol} / \mathrm{g}$. tissue in the insulin only group. Citric acid given at doses of $0.4 \mathrm{~g} / \mathrm{kg}$ or $1 \mathrm{~g} / \mathrm{kg}$ also significantly increased brain GSH levels by $90.6 \%$ and $114.5 \%$, respectively, compared to the insulin control group $(2.23 \pm 0.14$ and $2.51 \pm 0.11 \mathrm{vs}$. control value of $1.17 \pm 0.08 \mu \mathrm{mol} / \mathrm{g}$. tissue). (Fig. $1)$.

\subsection{Brain Paraoxonase-1}

In insulin only treated rats, brain PON-1 activity decreased significantly by $73.8 \%$ compared to the saline control $(3.01 \pm 0.24$ vs. $11.48 \pm 0.64 \mathrm{kU} / 1)$. In rats treated with insulin and citric acid at doses of $0.4 \mathrm{~g} / \mathrm{kg}$ and $1 \mathrm{~g} / \mathrm{kg}$, brain PON-1 activity increased by $164.1 \%$ and $183.0 \%$, respectively, compared to the insulin only group $(7.95 \pm 0.21$ and $8.52 \pm 0.35$ vs.3.01 $\pm 0.24 \mathrm{kU} / \mathrm{l}$ ) (Fig. 1).

\subsection{Brain Cholinesterase}

In rats treated with insulin alone, brain $\mathrm{BChE}$ activity decreased significantly by $30.4 \%$ compared to the saline control $(126.4 \pm 3.16$ vs. $181.7 \pm 4.35$ $\mathrm{U} / \mathrm{l})$. In the insulin/citric acid treated groups, BChE activity was restored to its saline control value (Fig. 2).

\subsection{Brain 5-lipoxygenase}

A significant increase in 5-lipoxygenase by $23.5 \%$ was observed in rats treated with only insulin as compared to their saline controls $(76.05 \pm 1.81$ vs. $61.6 \pm 0.77 \mathrm{ng} / \mathrm{ml})$.Citric acid given at $1 \mathrm{~g} / \mathrm{kg}$ significantly decreased the 5-lipoxygenase levels by $18.9 \%$ compared to the insulin control group (61.68 \pm 1.9 vs. $76.05 \pm 1.81 \mathrm{ng} / \mathrm{ml}$ ) (Fig. 2).
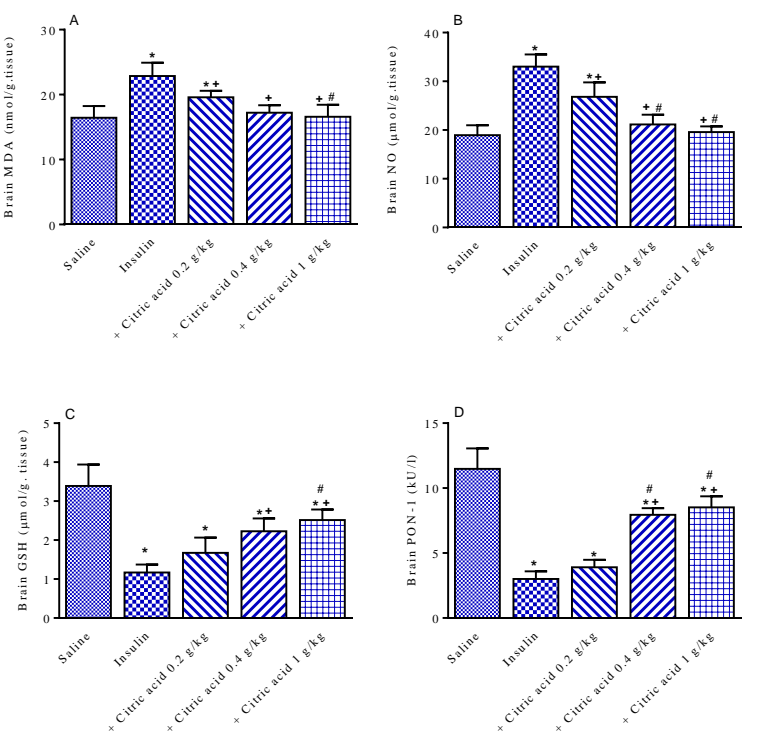

Fig. 1: Effect of citric acid on brain malondialdehyde (MDA), nitric oxide (NO), reduced glutathione (GSH), paraoxonase-1 activity in insulin-treated rats. ${ }^{*}$ : $\mathrm{P}<0.05$ vs. saline control and between different groups as shown on the figure. +: $\mathrm{P}<0.05$ vs. insulin only group. \#: $\mathrm{P}<0.05$ $v s$. insulin/citric acid $0.2 \mathrm{~g} / \mathrm{kg}$-treated group.

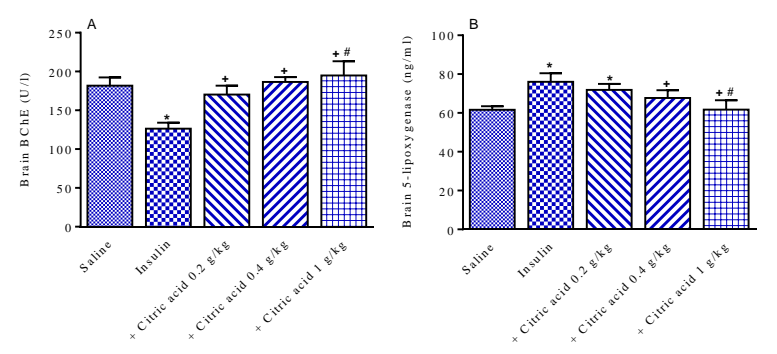

Fig. 2: Effect of citric acid on brain butyrylcholinesterase $(\mathrm{BChE})$ and 5-lipoxygenase in insulin-treated rats. *: $\mathrm{P}<0.05$ vs. saline control. +: $\mathrm{P}<0.05$ vs. insulin only group. \#: $\mathrm{P}<0.05$ vs. insulin/citric acid $0.2 \mathrm{~g} / \mathrm{kg}$-treated group.

\subsection{Liver Oxidative Stress}

\subsubsection{Lipid Peroxidation}

In rats treated with only insulin, liver MDA levels increased significantly by $95.1 \%$ compared to the saline control group $(59.52 \pm 1.51$ vs. $30.51 \pm 2.26$ nmol/g.tissue). Citric acid administered during hypoglycemia resulted in significant decrements in liver MDA level by $15.6 \%, 33.1 \%$ and $51.9 \%$ $(50.24 \pm 1.96,39.84 \pm 2.29$ and $28.6 \pm 1.1$ vs. 59.52 $\pm 1.51 \mathrm{nmol} /$ g.tissue) (Fig. 3). 


\subsubsection{Nitric Oxide}

The level of nitric oxide in the liver tissue increased significantly by $86.6 \%$ from $38.3 \pm 1.9 \mu \mathrm{mol} / \mathrm{g}$.tissue in the saline group to $71.46 \pm 2.66 \mu \mathrm{mol} / \mathrm{g}$.tissue in the insulin only group. In the insulin/citric acid treated groups, nitric oxide decreased significantly by $20.1 \%, 33.2 \%$ and $45.9 \%$ compared to the insulin control group $(57.06 \pm 2.67,47.71 \pm 1.92$ and 38.64 \pm 1.76 vs. control value of $71.46 \pm 2.66$ $\mu \mathrm{mol} / \mathrm{g}$.tissue) (Fig. 3).

\subsubsection{Reduced Glutathione}

There was a significant decline in liver GSH level by $36.1 \%$ in rats given only insulin compared to their saline controls $(3.59 \pm 0.24$ vs. $5.62 \pm 0.25$ $\mu \mathrm{mol} / \mathrm{g}$.tissue). However, liver GSH was significantly increased by $35.4 \%$ in the group that was treated with insulin/citric acid $1 \mathrm{~g} / \mathrm{kg}$ compared to the insulin only group (4.86 \pm 0.31 vs. $3.59 \pm$ $0.24 \mu \mathrm{mol} / \mathrm{g}$.tissue) (Fig. 3).

\subsection{Liver Paraoxonase-1}

After insulin treatment, liver PON-1 activity significantly decreased by $33.1 \%(16.18 \pm 0.95$ vs. $24.2 \pm 0.83 \mathrm{kU} / \mathrm{l})$ compared to the saline control group. Rats treated with insulin/citric acid at 0.4 $\mathrm{g} / \mathrm{kg}$ or $1 \mathrm{~g} / \mathrm{kg}$ showed significant increase in PON-1 activity by $24.6 \%$ and $42.8 \%$ compared to those given only insulin $(20.16 \pm 1.0$ and $23.1 \pm 0.72$ vs. $16.18 \pm 0.95 \mathrm{kU} / \mathrm{l})$ (Fig. 3).
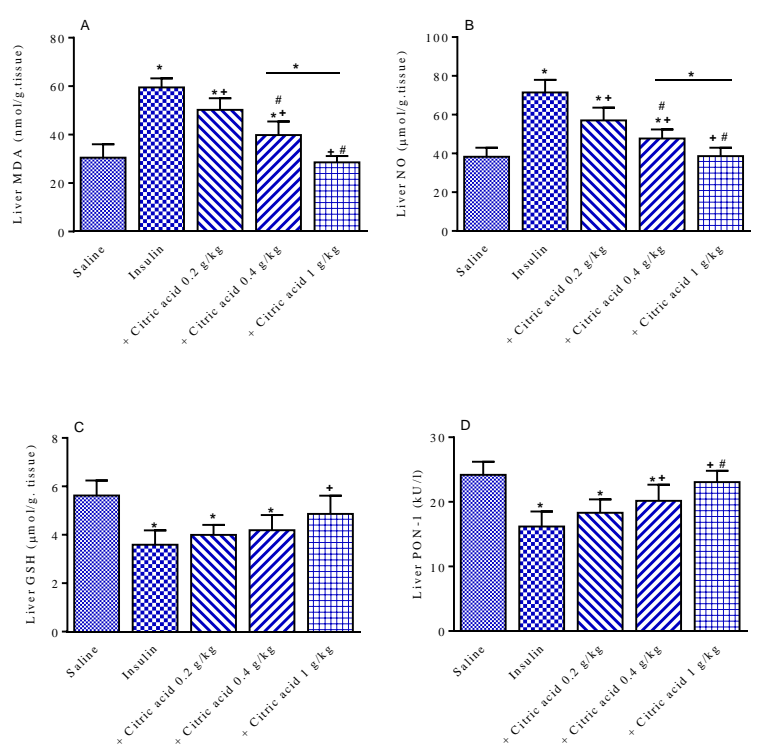

Fig. 3: Effect of citric acid on liver malondialdehyde (MDA), nitric oxide (NO), reduced glutathione (GSH), paraoxonase-1 activity in insulin-treated rats. *: $\mathrm{P}<0.05$ vs. saline control and between different groups as shown on the figure. + : $\mathrm{P}<0.05$ vs. insulin only group. \#: $\mathrm{P}<0.05$ vs. insulin/citric acid $0.2 \mathrm{~g} / \mathrm{kg}$-treated group.

\subsection{Serum Liver Enzymes}

After insulin injection, the activities of AST and ALT in serum were significantly increased by $74.5 \%(93.7 \pm 3.6$ vs. $53.71 \pm 1.5 \mathrm{U} / 1)$ and $80.0 \%$ $(107.3 \pm 2.4$ vs. $59.6 \pm 1.7 \mathrm{U} / 1)$ compared to the saline control values. The treatment of rats with citric acid at $400 \mathrm{mg} / \mathrm{kg}$ or $1 \mathrm{~g} / \mathrm{kg}$ significantly decreased serum ALT and AST. Serum ALT decreased from $93.7 \pm 3.6 \mathrm{U} / 1$ in the insulin only group to $69.2 \pm 1.85 \mathrm{U} / 1$ and $61.2 \pm 1.48 \mathrm{U} / 1$ in the insulin/citric acid groups. Meanwhile, serum AST decreased from control value of $107 \pm 2.4 \mathrm{U} / 1$ to $93.7 \pm 2.1 \mathrm{U} / 1$ and $69.5 \pm 1.86 \mathrm{U} / 1$, respectively (Fig. $4)$.
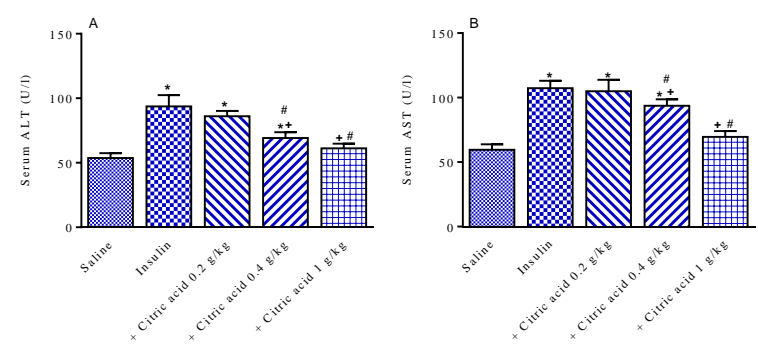

Fig. 4: Effect of citric acid on serum alanine aminotransferase (ALT) and aspartate aminotransferase (AST) in insulin-treated rats. *: $\mathrm{P}<0.05$ vs. saline control. +: $\mathrm{P}<0.05$ vs. insulin only group. \#: $\mathrm{P}<0.05$ vs. insulin $/$ citric acid $0.2 \mathrm{~g} / \mathrm{kg}$ treated group.

\subsection{Liver Histopathological Results}

H\&E stained sections of liver from the saline control group revealed normal features of hepatic architecture, the hepatic lobules being arranged in cords of hepatocytes radiating from the central veins (Fig. 5A). Sections from liver tissues of rats treated with insulin only showed that hepatic architecture was disorganized with marked affection of the hepatocytes in the form of hydropic degeneration, extensive vacuolation of the cytoplasm of hepatocytes, some nuclei appeared dark and others were karyolytic. The central vein appeared congested. Dilatation, congestion of portal vein, hyperplasia of bile ducts, pre portal necrosis, fibrosis and thickening of portal vein vascular wall were seen. Most of the blood sinusoids appeared narrow or obliterated (Figs. 5B \& 5C). In rats treated with insulin and subjected to citric at 0.2 $\mathrm{g} / \mathrm{kg}$, the liver still suffered from the deleterious effect induced by hypoglycaemia in the form of extensive vacuolation of their cytoplasm. Some 
nuclei appeared dark while others showed karolysis or karyorrhexis and binucleated cells, swelling or hydropic change. Dilated, congested portal vein, inflammatory infiltrate and fibrosis were observed (Fig. 5D \& 5E). Sections from liver tissue of rats treated with insulin and citric acid at $0.4 \mathrm{~g} / \mathrm{kg}$ showed variable degree of improvement in the form of some hepatocyte appearing normal but the distortion in hepatic architecture was not reversed. The portal vein appeared dilated, congested with thickening of portal vein vascular wall, and fibrosis. Some hepatocytes still suffered from karyolysis, karyorrhexis, vacuolated cytoplasm (Fig. 5F \& 5G). The histological sections from the group treated with insulin and citric acid at $1 \mathrm{~g} / \mathrm{kg}$ revealed more or less preserved hepatic architecture. The hepatocytes were arranged in cords radiating from dilated and congested central veins and separated by normal blood sinusoids and Kupffer cells (Fig. 5H).

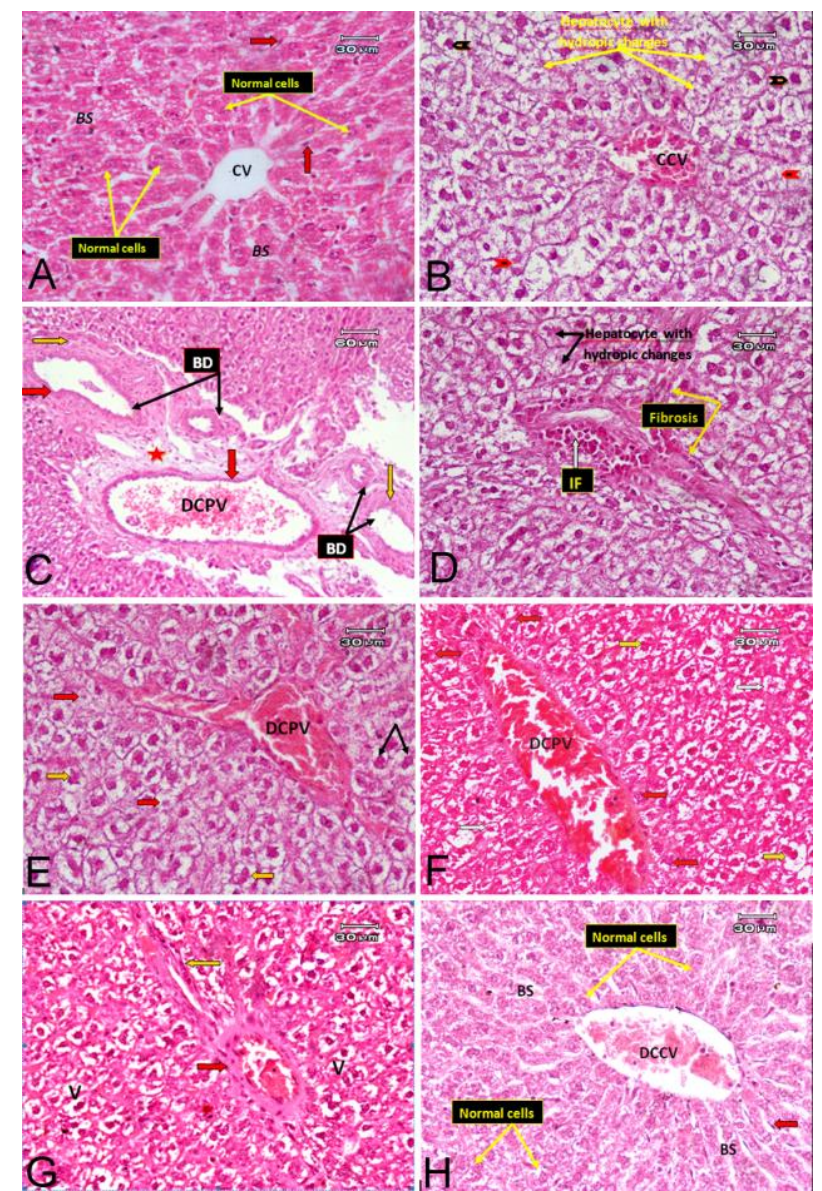

Fig. 5: Photomicrographs of Hx\& E stained sections of the rat liver after treatment with: (A) Saline control showing the classical hepatic architecture. Hepatocytes are arranged in cords radiating from the central vein $(\mathrm{CV})$ and separated by blood sinusoids (BS).The Blood sinusoids separating the hepatic cords are seen lined by Kupffer cells (red arrow) and endothelial cells. (B) Insulin showing disorganized hepatic architecture with extensive vacuolation of cytoplasm of hepatocytes, swelling or hydropic changes (yellow arrow), dark nuclei (black arrow), karolytic nuclei (red arrow), congested central vein (CCV). (C) Insulin (another filed) showing dilated congested portal vein (DCPV) with thickened wall (red arrow), hyperplasia of bile duct (BD), fibrosis (orange arrow), preportal necrosis (star). (D) Insulin + citric acid $0.2 \mathrm{~g} / \mathrm{kg}$ showing extensive vacuolation of their cytoplasm, hydropic degeneration in hepatocytes, fibrosis (yellow arrow), and inflammatory cell infiltrate (IF). (E) Insulin + citric acid $0.2 \mathrm{~g} / \mathrm{kg}$ (another filed) showing dilated and congested portal vein (DCPV), dark nuclei, karolytic nuclei (red arrow), karyorrhexis (orange arrow) and binucleated cells (black arrow). (F) Insulin + citric acid $0.4 \mathrm{~g} / \mathrm{kg}$ showing some normal hepatocytes (red arrow), some karyolytic hepatocytes (white arrow), karyorrhexis (orange arrow), dilated congested portal vein (DCPV). (G) Insulin + citric acid 0.4 $\mathrm{g} / \mathrm{kg}$ (another filed) showing vacuolated cytoplasm (v), thickening of portal vein wall (red arrow), and fibrosis (orange arrow). (H) Insulin + citric acid 1 $\mathrm{g} / \mathrm{kg}$ showing normal hepatic architecture. The hepatocytes are arranged in cords radiating from dilated and congested central veins (DCCV) and separated by normal blood sinusoids (BS) and Kupffer cells (red arrow).

\section{Discussion}

The present study provided the evidence that orally administered citric acid during insulin-induced hypoglycaemia was able to alleviate the increase in oxidative stress biomarkers in brain and liver tissue, reduced the elevation in serum aminotransferases and provide histologic protection against liver damage. In these experiments, severe hypoglycaemia resulted in significant increase in lipid peroxidation as evidenced by the rise in the level of malondialdehyde. Other studies also reported significant increments in brain MDA $[8,10]$ and increased expression of 4-hydroxy-2-nonenal [9] indicative of oxidative damage after insulininduced hypoglycemia. This suggests increased ROS during hypoglycaemia and consequent attack on cell polyunsaturated fatty acids. In addition, reduced glutathione, an intracellular antioxidant and free radical scavenger [32] showed significant decrease in brain and liver tissue of hypoglycaemic rats. This might be caused by increased consumption of the antioxidant by the increase in ROS or decreased energy supply and failure to resynthesize reduced glutathione. In this study, 
treatment of hypoglycaemic rats with citric acid was found to attenuate the increments in brain and liver malondialdehyde and increase reduced glutathione levels, which is suggestive of an antioxidant effect for citric acid.

Our results also indicate a significant increase in nitric oxide levels in brain and liver tissues which is in agreement with previous studies [10]. Nitric oxide $(\mathrm{NO} \bullet$ ), a short-lived free radical and signaling molecule is involved in important physiological functions such as neurotransmission and control of vascular tone. It is generated from L-arginine by the action of nitric oxide synthase (NOS). Two constitutive isoforms are found in endothelial cells (eNOS) and neurons (nNOS) and these generate small amounts of nitric oxide for short period of time. A third inducible isoform (iNOS) is induced in macrophages by proinflammatory cytokines and LPS and is responsible for the overproduction of nitric oxide during inflammatory conditions. The excessive increase in nitric oxide can lead to cell death [34]. The neurotoxic actions of nitric oxide thought to be largely mediated by peroxynitrite (ONOO-), derived from the reaction of nitric oxide and superoxide and also by nitrogen oxides, resulting in oxidation, nitrosation, and nitration of proteins and DNA [35]. In the present study, however, treatment with citric acid prevented the increase in tissue nitric oxide during hypoglycaemia. This suggests that the protective effect of citric acid against liver damage could at least in part be due to a decrease in nitric oxide concentrations.

We also demonstrated marked and significant inhibition of PON-1 activity in brain and liver during hypoglycaemia which supports our previous observations [10]. The PON-1 enzyme is synthesized by the liver and circulates bound mainly to high-density lipoproteins and functions to protect the oxidation of low-density lipoprotein [36,37]. It hydrolyzes several organophosphates, carbamates, nerve agents and many other xenobiotics [36]. It has been shown to inhibit the release of proinflammatory cytokines eg., TNF- $\alpha$, IL- 6 , and ROS from macrophages [38]. Moreover, deficiency of the enzyme was found to result in increased oxidative stress in serum and macrophages [39]. A decrease in activity was observed in chronic liver disease [40] and neurological disorders [41]. The enzyme is inactivated by oxidative stress [42]. Its inactivation results from an interaction between the enzyme free sulfhydryl group and oxidized lipids and can be prevented by antioxidants [43]. In this study, the decline in PON-1 activity during hypoglycaemia was prevented by citric acid, possibly due to lowered level of oxidative stress. Brain cholinesterase activity also decreased significantly during hypoglycaemia which is in accordance with previous reports [10]. Cholinesterase activity was restored to control value by treatment with citric acid, which is likely to a consequence of a neuroprotective effect for citric acid.

The 5-lipoxygenase catalyzes the oxidation of arachidonic acid to yield leukotrienes, including leukotriene B4 and cysteinyl leukotrienes, both are potent inflammatory lipid mediators. 5lipoxygenase is up-regulated in the aging brain and Alzheimer's disease [44,45]. The 5-lipoxygenase enzyme and its downstream leukotriene metabolites might have an important role in Alzheimer's disease pathogenesis [46]. Moreover, inactivation of this enzyme was shown to reduce hepatic inflammation, suppress hepatic stellate cell activation, liver injury and fibrosis $[47,48]$. In this study, we demonstrated a significant increase in brain 5-lipoxygenase in insulin-treated rats, thereby, suggesting an inflammatory mechanism underlying the development of neuronal and liver injury during hypoglycemia. We also showed that the increased level of brain 5-lipoxygenase could be reduced by treatment with citric acid. Such anti-inflammatory property of citric acid could prove of benefit in neurodegenerative and liver disorders.

The antioxidant and anti-inflammatory effects of citric acid reported herein is supported by previous findings. Studies in LPS-treated mice showed that orally given citric acid $(1-2 \mathrm{~g} / \mathrm{kg})$ attenuated the elevations in brain MDA, nitrite, TNF- $\alpha$ and increased glutathione peroxidase (GPx) activity. Citric acid also decreased nitrite, increased GPx activity, decreased DNA fragmentation, serum transaminases, caspase-3, and iNOS expression and protected against LPS-induced liver damage [20]. In rotenone-treated mice, orally given citric acid decreased MDA, nitric oxide, and increased total antioxidant capacity in brain and liver. It also reduced the elevation in NF- $\mathrm{KB}$ level in the brain and prevented histopathological changes in brain and liver of rotenone-treated mice [21].

The mechanisms by which citric acid protects the brain and liver during hypoglycaemia might also involve improved cell bioenergitics, whereby, citric acid through Kreb's cycle is used to generate energy through the oxidation of the acetyl component of 
acetyl-CoA derived from carbohydrates, fats, and amino acids [14]. In this context, it has been shown that provision of substrates of Kreb's cycle such as $\alpha$-ketoglutarate or pyruvate protected against neuronal death caused by the activation of poly (ADP-ribose) polymerase-1 (PARP1) and the consequent impairment of glycolysis [49]. Moreover, pyruvate prevented the excitotoxic neuronal damage evoked by $N$-methyl-D-aspartate (NMDA) in rat hippocampal slices [50], whereas $\beta$ hydroxybutyrate was able to inhibit lipid peroxidation that followed severe hypoglycemia in the rat [51].

\section{Conclusion}

In summary, we showed that orally given citric acid significantly attenuated brain and liver oxidative stress and liver damage in response to severe hypoglycaemia. Citric acid might exert its protective effect via an antioxidant and anti-inflammatory actions or by provision of energy substrates through stimulation of glycolysis and the tricarboxylic acid cycled.

\section{References:}

[1] Jensen VF, Bogh IB, Lykkesfeldt J. Effect of insulin-induced hypoglycaemia on the central nervous system: evidence from experimental studies. Journal of Neuroendocrinology 2014; 26(3):123-50.

[2] Suh SW, Hamby AM, Gum ET, Shin BS, Won SJ, Sheline CT, et al. Sequential release of nitric oxide, zinc, and superoxide in hypoglycemic neuronal death. Journal of Cerebral Blood Flow \& Metabolism 2008; 28(10):1697-706.

[3] Puente EC, Silverstein J, Bree AJ, Musikantow DR, Wozniak DF, Maloney S, et al. Recurrent moderate hypoglycemia ameliorates brain damage and cognitive dysfunction induced by severe hypoglycemia. Diabetes 2010; 59:10551062.

[4] Won SJ, Kim JH, Yoo BH, Sohn M, Kauppinen TM, Park MS, et al. Prevention of hypoglycemia-induced neuronal death by minocycline. Journal of Neuroinflammation 2012; 9:225.

[5] Languren G, Montiel T, Julio-Amilpas A, Massieu L. Neuronal damage and cognitive impairment associated with hypoglycemia: an integrated view. Neurochemistry International 2013; 63(4):331-43.
[6] Cryer PE. Hypoglycemia, functional brain failure, and brain death. Journal of Clinical Investigation 2007; 117(4):868-870.

[7] Languren G, Montiel T, Ramirez-Lugo L, Balderas I, Sanchez-Chavez G, Sotres-Bayon F, et al. Recurrent moderate hypoglycemia exacerbates oxidative damage and neuronal death leading to cognitive dysfunction after the hypoglycemic coma. Journal of Cerebral Blood Flow \& Metabolism 2019; 39(5):808-821.

[8] Patockova J, Marhol P, Tumova E, Krsiak M, Rokyta R, Stipek S, et al. Oxidative stress in the brain tissue of laboratory mice with acute post insulin hypoglycemia. Physiological Research 2003; 52(1):131-135.

[9] Won SJ, Yoo BH, Kauppinen TM, Choi BY, Kim JH, Jang BG, et al. Recurrent/moderate hypoglycemia induces hippocampal dendritic injury, microglial activation, and cognitive impairment in diabetic rats. Journal of Neuroinflammation 2012, 9:182.

[10] Abdel-Salam OME, Sleem AA, Youness ER, Morsy FA, Shaffie NM, Souleman AMA. Hot pepper extract protects against hypoglycemiainduced brain and liver injury in mice. Reactive Oxygen Species 2019; 8(23):297-311.

[11] Halliwell B. Reactive oxygen species in living systems: source, biochemistry, and role in human disease. American Journal of Medicine 1991; 91:14S-22S.

[12] Halliwell B. The wanderings of a free radical. Free Radical Biology \& Medicine 2009; 46(5):531-42.

[13] Figueira TR, Barros MH, Camargo AA, Castilho RF, Ferreira JC, Kowaltowski AJ, et al. Mitochondria as a source of reactive oxygen and nitrogen species: from molecular mechanisms to human health. Antioxidants \& Redox Signaling 2013; 18(16):2029-74.

[14] Fromm HJ, Hargrove MS. The tricarboxylic acid cycle. In: Essentials of Biochemistry (Fromm HJ, Hargrove MS, eds). SpringerVerlag, Berlin, Heidelberg. 2012, pp. 205-21.

[15] Grigor JMV, Johnson WS, Salminen S: Food additives for special dietary purposes. In: Food Additives, $2^{\text {nd }}$ edition. (Branen AL, Davidson PM, Salminen S, Thorngate JH 3rd, eds.) Marcel Dekker, Inc., Basel, New York, 2002, pp. 341.

[16] Penniston KL, Nakada SY, Holmes RP, Assimos DG. Quantitative assessment of citric acid in lemon juice, lime juice, and commercially-available fruit juice products. Journal of Endourology 2008; 22(3): 567-570 
[17] Gabutti L, Ferrari N, Mombelli G, Keller F, Marone C. The favorable effect of regional citrate anticoagulation on interleukin-1beta release is dissociated from both coagulation and complement activation. Journal of Nephrology 2004; 17(6): 819-825.

[18] Gritters M, Grooteman MP, Schoorl M, Schoorl M, Bartels PC, Scheffer PG, et al. Citrate anticoagulation abolishes degranulation of polymorphonuclear cells and platelets and reduces oxidative stress during haemodialysis. Nephrology Dialysis Transplantation 2006; 21(1): 153-159.

[19] Tiranathanagul K, Jearnsujitwimol O, Susantitaphong P, Kijkriengkraikul N, Leelahavanichkul A, Srisawat N, et al. Regional citrate anticoagulation reduces polymorphonuclear cell degranulation in critically ill patients treated with continuous venovenous hemofiltration. Therapeutic Apheresis and Dialysis 2011; 15(6): 556-564.

[20] Abdel-Salam OM, Youness ER, Mohammed NA, Morsy SM, Omara EA, Sleem AA. Citric acid effects on brain and liver oxidative stress in lipopolysaccharide-treated mice. Journal of Medicinal Food 2014; 17(5):588-598.

[21] Abdel-Salam OME, Morsy SMY, Youness ER, Yassen NN, Shaffie N, Sleem AA. Citric acid protects dopaminergic cells against rotenoneinduced neurodegeneration. Reactive Oxygen Species 2020; 9(27):118-135.

[22] Abdel-Salam OM, Youness ER, Mohammed NA, Yassen NN, Khadrawy YA, El-Toukhy SE, et al. Novel neuroprotective and hepatoprotective effects of citric acid in acute malathion intoxication. Asian Pacific Journal of Tropical Medicine 2016; 9(12):1181-94.

[23] Abdel-Salam OME, Sleem AA, Morsy FA. Citric acid protects against toluene-induced brain neurodegeneration and liver damage in rats. Journal of Basic Pharmacology and Toxicology 2020;4(2):38-48.

[24] Abdel Salam OME, Sleem AA, Shaffie NM. Protection against carbon tetrachloride-induced liver damage by citric acid. Cell Biology: Research \& Therapy 2015, 4:1

[25] Abdel-Salam OME, Shaffie NM, Omara EA, Yassen NN. Citric Acid an Antioxidant in Liver. In: Vinood Patel, editors: The Liver: Oxidative Stress and Dietary Antioxidants, Chennai: Academic Press; 2018, pp. 183-198.

[26] Nair V, Turner GA. The thiobarbituric acid test for lipid peroxidation: structure of the adduct with malondialdehyde. Lipids 1984; 19:804 805.
[27] Moshage H, Kok B, Huizenga JR, Jansen PL. Nitrite and nitrate determinations in plasma: a critical evaluation. Clinical Chemistry 1995; 41(6 Pt 1):892-896.

[28] Ellman GL. Tissue sulfhydryl groups. Archives of Biochemistry and Biophysics 1959; 82:70-77.

[29] Haagen L, Brock A. A new automated method for phenotyping arylesterase (EC 3.1.1.2) based upon inhibition of enzymatic hydrolysis of 4nitrophenyl acetate by phenyl acetate. European Journal of Clinical Chemistry and Clinical Biochemistry1992; 30:391-395.

[30] Ellman GL, Courtney KD, Andres V, Jr., Feather-Stone RM. A new and rapid colorimetric determination of acetylcholinesterase activity. Biochemical Pharmacology 1961; 7:88-95.

[31] Crowley LV. The Reitman-Frankel colorimetric transaminase procedure in suspected myocardial infarction. Clinical Chemistry 1967; 13: 482-487.

[32] Meister A, Anderson ME. Glutathione. Annual Review of Biochemistry 1983; 52:711-760.

[33] Förstermann U, Sessa WC. Nitric oxide synthases: regulation and function. European Heart Journal 2012;33:829-37, 837a-837d.

[34] Wink DA, Feelisch M, Vodovotz Y, Fukuto J, Grisham MB. The chemical biology of nitric oxide. In: Gilbert, Colton, editors. Reactive oxygen species in biological systems. New York: Kluwer Academic/Plenum Publishers; 1999, p. 245-291.

[35] Brown GC. Nitric oxide and neuronal death. Nitric Oxide 2010; 23(3):153-165.

[36] La Du BN. Human serum paraoxonase:arylesterase. In: Pharmacogenetics of DrugMetabolism (W Kalow). Pergamon Press, NewYork, NY, USA, 1992, pp. 51-91.

[37] Watson AD, Berliner JA, Hama SY, La Du BN, Faull KF, Fogelman AM, et al. Protective effect of high density lipoprotein associated paraoxonase. Inhibition of the biological activity of minimally oxidized low-density lipoprotein. Journal of Clinical Investigation 1995; 96(6):2882-91.

[38] Aharoni S, Aviram M, Fuhrman B. Paraoxonase 1 (PON1) reduces macrophage inflammatory responses. Atherosclerosis 2013;228:353-361..

[39] Rozenberg O, Rosenblat M, Coleman R, Shih DM, Aviram M. Paraoxonase (PON1) deficiency is associated with increased macrophage oxidative stress: studies in PON1knockout mice. Free Radical Biology and Medicine 2003; 34(6): 774-784. 
[40] Ferre N, Camps J, Prats E, Vilella E, Paul A, Figuera L, Joven J. Serum paraoxonase activity: a new additional test for the improved evaluation of chronic liver damage. Clinical Chemistry 2002; 48:261-268.

[41] Menini T, Gugliucci A. Paraoxonase 1 in neurological disorders. Redox Report 2014;19:49-58.

[42] Yang Nguyen SD, Hung ND, Cheon-Ho P, Ree KM, Dai-Eun S. Oxidative inactivation of lactonase activity of purified human paraoxonase 1 (PON1). Biochimica et Biophysica Acta 2009; 1790(3): 155-160.

[43] Aviram M, Rosenblat M, Billecke S, Erogul J, Sorenson R, Bisgaier CL, et al. Human serum paraoxonase (PON 1) is inactivated by oxidized low density lipoprotein and preserved by antioxidants. Free Radical Biology \& Medicine 1999; 26(7-8):892-904.

[44] Uz T, Pesold C, Longone P, Manev H. Agingassociated up-regulation of neuronal 5lipoxygenase expression: putative role in neuronal vulnerability. FASEB Journal 1998; 12(6):439-449.

[45] Czapski GA, Czubowicz K, Strosznajder JB, Strosznajder RP. The lipoxygenases: their regulation and implication in Alzheimer's disease. Neurochemistry Research 2016; 41(12): 243-57.

[46] Chu J, Praticò D. The 5-Lipoxygenase as modulator of Alzheimer's $\gamma$-secretase and therapeutic target. Brain Research Bulletin 2016; 126(Pt 2): 207-212.

[47] Horrillo R, Planagumà A, González-Périz A, Ferré N, Titos E, Miquel R, López-Parra M, et al. Comparative protection against liver inflammation and fibrosis by a selective cyclooxygenase- 2 inhibitor and a nonredox-type 5-lipoxygenase inhibitor. Journal of Pharmacology and Experimental Therapeutics 2007; 323 (3):778-786.

[48] Martínez-Clemente M, Ferré N, González-Périz A, López-Parra M, Horrillo R, Titos E et al. 5lipoxygenase deficiency reduces hepatic inflammation and tumor necrosis factor $\alpha$ induced hepatocyte damage in hyperlipidemiaprone ApoE-null mice. Hepatology 2010; 51(3): 817-827.

[49] Ying W, Chen Y, Alano CC, Swanson RA. Tricarboxylic acid cycle substrates prevent PARP-mediated death of neurons and astrocytes. Journal of Cerebral Blood Flow \& Metabolism 2002; 22(7):774-779.

[50] Izumi Y, Zorumski CF. Neuroprotective effects of pyruvate following NMDA-mediated excitotoxic insults in hippocampal slices. Neuroscience Letters 2010; 478(3):131-135.

[51] Haces ML, Hernandez-Fonseca K, MedinaCampos ON, Montiel T, Pedraza-Chaverri J, Massieu L. Antioxidant capacity contributes to protection of ketone bodies against oxidative damage induced during hypoglycemic conditions. Experimenal Neurology 2008; 211(1):85-96.

\section{Competing Interests:}

No competing interests to disclose.

Contribution of Individual Authors to the Creation of a Scientific Article (Ghostwriting Policy)

All authors contributed equally to the manuscript, read and approved the final version.

\section{Sources of Funding for Research Presented in a Scientific Article or Scientific Article Itself}

This work is not supported by research grants.

\section{Creative Commons Attribution License 4.0 (Attribution 4.0 International, CC BY 4.0)}

This article is published under the terms of the Creative Commons Attribution License 4.0 https://creativecommons.org/licenses/by/4.0/deed.en _US

\section{Publication Ethics for Researches Involving Human Subjects \\ Not applicable.}

\section{Publication Ethics for Researches Involving Animals}

The study was conducted in accordance with the recommendations the recommendations of the National Institutes of Health Guide for Care and Use of Laboratory Animals (Publication No. 85-23, revised 1985) and the recommendations for the proper care and use of laboratory animals (Directive 2010/63/EU revising Directive 86/609/EEC on the protection of animals used for scientific purposes). The article is comply with the guidelines of ARRIVE.

\section{Publication Ethics for Researches Involving Plants}

Not applicable. 